\title{
Overview of Steel Slag Application and Utilization
}

\author{
J.W. Lim ${ }^{1,2}$, L.H. Chew ${ }^{2}$, Thomas S.Y. Choong ${ }^{2}$, C. Tezara ${ }^{1}$ and M.H. Yazdi ${ }^{1,3}$ \\ ${ }^{1}$ Department of Mechanical Engineering, INTI International University, Jalan BBN 12/1, Bandar Baru Nilai, 71800 Nilai, Negeri \\ Sembilan,Malaysia
}

${ }^{2}$ Department of Chemical and Environmental Engineering, Universiti Putra Malaysia, 43400 Selangor, Malaysia

${ }^{3}$ Department of Mechanical Engineering, Islamic Azad University, Mashhad Branch, Mashhad, Iran

\begin{abstract}
Significant quantities of steel slag are generated as waste material or byproduct every day from steel industries. Slag is produced from different types of furnaces with different operating conditions. Slag contains Ferrous Oxide, Calcium Oxide, Silica etc. Physical and chemical properties of slag are affected by different methods of slag solidification such as air cooled, steam, and injection of additives. Several material characterization methods, such as X-ray Diffraction (XRD), Scanned Electron Microscopy (SEM) and Inductive Coupled Plasma (ICP-OES) are used to determine elemental composition in the steel slag. Therefore, slags can become one of the promising materials in various applications such as in transportation industry, construction, cement production, waste water and water treatment. The various applications of steel slag indicate that it can be reused and utilized rather than being disposed to the landfill. This paper presents a review of its applications and utilization
\end{abstract}

\section{Introduction}

Steel are mainly produced from integrated steel mills which consist of Basic Oxygen Furnace (BOF) or Blast Furnace (BF). Meanwhile steel from scrap based materials are produced in Electrical Arc Furnace (EAF) operated mills. Steel slags have variety of compositions and in various forms after cooling. Most steel slags form hard rock-like materials upon cooling or solidification. However some slags can be reused to make dusty powders. There are different roles of steel slag in steelmaking process; as a sink for collecting impurities during steel refining process, to prevent diffusion N2and $\mathrm{H} 2$ gases from atmosphere to the molten steel, protecting steel against re-oxidation, as the barricade heat transfer from molten steel to the surrounding and as emulsifier for hot metal to promote carbon oxidation. Slags are porous, large surface area with suitable hydraulic conductivity [1] (Figure 1).The different application and utilization of steel slag are briefly described in the following section. The main byproducts produced during iron and crude steel production are slags $(90 \%)$, dusts and sledges that reported for three types of furnaces.

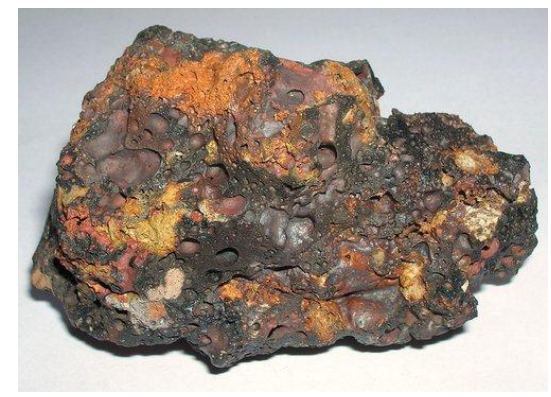

Figure 1: Slag as a by-product from steel making furnace [2]

\section{Applications of Steel slag}

According to the Malaysia Environmental Quality (Scheduled Waste) Regulation (2005), Steel slag is classified as non-hazardous waste which can be disposed off to appropriate landfills. The disposal of steel slag requires large landfill area which is rather unfavourable in economical terms. Therefore, several research and development have been conducted to establish the potential use of slag in different applications. However, it might have the risk that different components of slag might elute, especially on the heavy metal. Therefore, it is necessary to examine this metallurgical waste material in appropriate ways. Typical applications of steel slags are sealing aggregate (skid resistant), asphalt aggregate, base, sub-base, construction fills, subsoil drains, grit blasting and waste water treatment. The various applications for steel slag in 2010 (22.3 million tonnes) is illustrated in Figure 2

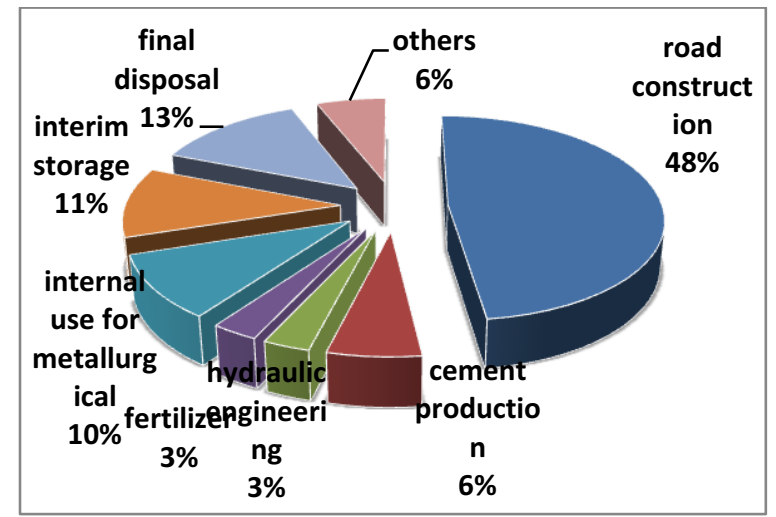

Figure 2: Statistical data of various applications of steel slag (2010) [3]

\subsection{Cement Productions}


In cement and concrete industries, slag can be used either as an aggregate or binder in stabilized base courses. In order to conserve natural resources and reduce environmental impact, slags can be used as an aggregate. To diminish the need for cement which is expensive in cost, slag is replaced and used as a binder. Because of these advantages, many researchers have examined adding slag content to cement and concrete [4]. Addition of slag to cement presents some important technical advantages over ordinary Portland cements. These benefits can be enumerated as development of mechanical strengths, low solubility of the hydrates and porosity, lower heat of hydration, excellent durability and stronger aggregate-matrix interface. However, there are some disadvantages such as high shrinkage, formation of micro-cracks and rapid setting. Therefore, the combination of various type of slags (activated, chemical and physical modified) to cement are investigated. For instance, it can boost the hydration ability of slag cement concretes, improving the mechanical performance of cement, enhancing the strengths of cement, autogenous deformation on the cracking, microstructure and durability, resistance.

\subsection{Road Construction}

Industrial by-products such as steel slag can be utilized instead of natural aggregates in order to prevent depletion of resources. Million tons of sand, till and crushed rocks were extracted from mines due to roads construction. It is well known that technical, economical and many environmental benefits are obtained when steel slag has been considered as alternative construction materials [5]. Due to prominent properties of steel slag, it is an ideal aggregate for asphalt surface course materials and road surface treatments. It has been proven that the use of steel slag in road construction mixtures has more advantage compared to conventional asphalt. The investigations of the asphalt mix and road surface have shown very good results in terms of stability, stiffness and durability. The slag asphalt, as expected, provided good friction values, noise reduction levels, enhances resistance to cracking at low temperatures with excellent performance in roughness and good resistance against water permeability[6].

\subsection{Water and Wastewater Treatment}

As slag has good sportive characteristics and is low cost, it is widely used in wastewater and water treatment, and may be the alternative of using granular activated carbon. Various research such as adsorptions of dye, heavy metals and organics were carried out by using steel slag. However, the uptake capacity of slag is dependent on the $\mathrm{pH}$ solution. The hydration of slag composition in the aqueous solutions provides a high $\mathrm{pH}$. The possible hydration reactions can be occurred with different compositions of slag as followings:

$$
\begin{aligned}
& \mathrm{CaO}+\mathrm{H}_{2} \mathrm{O} \rightarrow \mathrm{Ca}(\mathrm{OH})_{2} \\
& \mathrm{MgO}+\mathrm{H}_{2} \mathrm{O} \rightarrow \mathrm{Mg}(\mathrm{OH})_{2}
\end{aligned}
$$

$$
2 \mathrm{Ca}_{2} \mathrm{SiO}_{4}+4 \mathrm{H}_{2} \mathrm{O} \rightarrow 3 \mathrm{CaO} .2 \mathrm{SiO}_{2} \cdot 3 \mathrm{H}_{2} \mathrm{O}+\mathrm{Ca}(\mathrm{OH})_{2}
$$

$$
\begin{aligned}
& 2 \mathrm{Ca}_{3} \mathrm{SiO}_{5} \\
& 3 \mathrm{Ca}(\mathrm{OH})_{2}
\end{aligned}+6 \mathrm{H}_{2} \mathrm{O} \rightarrow 3 \mathrm{CaO} .2 \mathrm{SiO}_{2} \cdot 3 \mathrm{H}_{2} \mathrm{O}+
$$

$$
\mathrm{CaO} .7 \mathrm{Al}_{2} \mathrm{O}_{3}+12 \mathrm{H}_{2} \mathrm{O} \rightarrow \mathrm{CaO} .7 \mathrm{Al}_{2} \mathrm{O}_{3} \cdot 6 \mathrm{H}_{2} \mathrm{O}+
$$$$
6 \mathrm{Al}_{2} \mathrm{O}_{3} \cdot \mathrm{H}_{2} \mathrm{O}
$$

With the high $\mathrm{pH}$ condition, the slag surface is negatively charged and adsorption metal ions especially cations are preferred. However, heavy metal absorption by using slags can be conducted with a condition of either high temperature or low $\mathrm{pH}$ under certain conditions. Yamashita et al. investigated the possible mechanisms of removing dissolved heavy metals from aqueous waste liquids via the converter furnace slag [7]. They suggested that the removal can be attributed to one or more of following effects: adsorption, coprecipitation, hydroxide precipitation as hydroxide, sulphide and ion exchange.

Wastewater from the steel mill contains a high concentration of heavy metals due to the accumulation of filtered particles from the filtration process of wastewater. A direct release of the backwash water into the environment may cause serious effects to both land and aquatic lives. Based on the toxilogical studies, metals are toxic and non-biodegradable and may continue to exist in these water bodies. Furthermore, the heavy metals also have the tendency to accumulate in the food chain. Hence, a strict environmental regulation has been established in an effort to mitigate the heavy metals contamination of the discharge of industrial effluent. Absorption of lead ions by two different types steel slag was carried out in column-type contact process [8]

\subsection{Phosporus Removal}

Phosphorus (P) from agricultural wastewater is one of the major pollutants in natural water that cause the algae growth and eutrophication of lakes. Therefore, Phosphorus is one of the major nutrients that is need to be removed from domestic wastewater before being discharged into water bodies. The application of an appropriate technology to remove the maximum capacity of nutrient is imperative. In order to remove phosphorus from wastewater, various methods or approaches have been attempted, including biological, chemical process (precipitation, metal salt addition) and physical (electro-dialysis, reverse osmosis). Among all the methods, the chemical precipitation is expensive and increasing sludge volume by up to $40 \%$. The biological phosphorus removal needs a lot more volume or space (anaerobic unit) than the other processes. Various research on the potential use of industrial byproducts to remove $\mathrm{P}$ from wastewater was studied in the late $1980 \mathrm{~s}$.

The $\mathrm{P}$ removal is along with the development of constructed wetlands (CW). This method is a low cost technology for pollutions treatment, which slag 
performs an important role in absorbing impurities especially phosphorus. By comparing most of industrial by products, steel slag is a low-cost and abundant material, which its combination with small secondary treatment systems (such as constructed wetlands) is preferred in compared to the others methods $[9,10]$. The slag contains various metal oxides such as iron oxides and alumina that may be effective in $P$ reduction from domestic, agricultural effluents and municipal [11]. Steel Slag is a light weight porous medium with numerous sites for sorption. Steel slags have different physic-chemical property due to various feedstock ores, fluxes and manufacturing process. These differences caused a board range of $\mathrm{P}$ sorption capacity by using slag, ranging from 76.4 to 8390 $\mathrm{mg} / \mathrm{kg}$. Many experiments have been carried out in laboratory to evaluate the sorption capacity of slag. These studies have found slag to be a promising substrate for P-removal [12].

\section{Steel Slag Characterization}

\subsection{Scanned Electron Microscopy (SEM)}

SEM is a device that utilizes focused beam of high energy electrons to analyze solid material by obtaining topographical, morphological and compositional information of the tested sample. A scanning electron microscope (model S-3400N, HITACHI, Japan) was used to obtain external morphology, crystalline structure and orientation of materials making up the sample at an accelerating voltage of $20.0 \mathrm{kV}$, beam current of $50 \mathrm{~mA}$ and working distance of $9.0 \mathrm{~mm}-$ $10.0 \mathrm{~mm}$ using backscattered electrons (BSE) objective with aperture of 3 . Two images were captured at a low magnification $(300 \times)$ and high magnification $(1000 \times)$ respectively.

The micrographic appearance of the unreacted EAFS shows distinct mineral phases, presented in Figure 3. The light areas contain a higher proportion of $\mathrm{Fe}, \mathrm{Mg}$, $\mathrm{Mn}$ and $\mathrm{Al}$ while the dark areas contain a higher proportion of CA and Si (Bankole et al., 2014). From Figure 3, it can be seen that the light areas are larger than the dark areas. This indicates a higher composition of $\mathrm{Fe}, \mathrm{Mg}, \mathrm{Mn}$ and $\mathrm{Al}$ compared to the composition of $\mathrm{Ca}$ and $\mathrm{Si}$

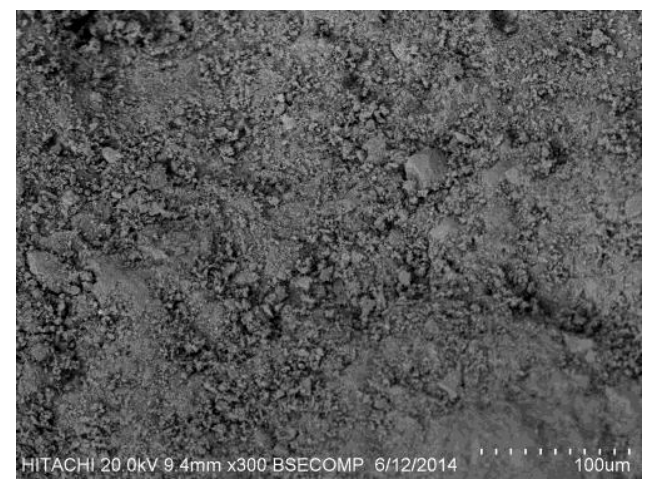

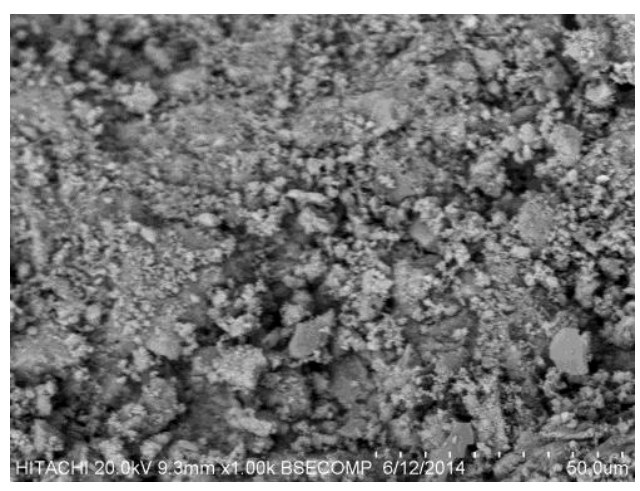

Figure 3: SEM micrograph of unreacted EAFS at magnification of (a) 300x and (b) 1000x

\subsection{X-Ray Diffraction (XRD)}

X-Ray diffractometer (model XRD-600, Shimadzu, Japan) was used for phase identification of unreacted EAFS with $\mathrm{Cu} \mathrm{K} \alpha$ radiation at $40 \mathrm{kV}$ and $40 \mathrm{~mA}$ and scanned between $2 \theta=20^{\circ}-80^{\circ}$ and scanning speed of $0.1 \% \mathrm{~min}$. The X-Ray diffraction pattern observation was generated by using powder diffraction method. The XRD pattern was then analyzed using X'Pert High Score Plus software to obtain the mineralogical and chemical composition of the sample slag. Each crystalline solid has its unique characteristic XRD pattern which may be used for its identification. X'Pert High Score Plus software has the database of these XRD patterns so that they could be used to match with the peaks appear in the XRD pattern of unreacted EAFS. Once all the peaks were identified for the chemicals present in the sample slag, the intensity under the peaks was automatically used by the software to determine their composition.

The XRD analysis of unreacted EAFS is shown in Figure 4. The diffraction pattern is heterogeneous, consisting of a mixture of crystalline phases. The analysis identifies calcium oxide $(\mathrm{CaO})$, silicon oxide (SiO2), hematite (Fe2O3), manganese (III) oxide (Mn2O3), magnesium oxide $(\mathrm{MgO})$, aluminium oxide (A12O3), phosphorus oxide (P2O5), metallic iron (Fe), srebrodolskite (Ca2Fe2O5), dicalcium silicate (Ca2SiO4) and pyroxene (CaAl2SiO6).

The mineralogical composition of steel slags was studied by several researchers. The XRD analysis of steel slags shows a complex structure. Many overlapping peaks appear in XRD patterns indicates the presence of crystalline phases in the steel slag [14]. The more crystalline structured compound has its XRD peaks more easily to be identified [15]. The common mineral phases presents in steel slag include two- and three-component compositions of the type $\mathrm{CaO}-\mathrm{SiO} 2$, $\mathrm{CaO}-\mathrm{Fe} 2 \mathrm{O} 3, \mathrm{CaO}-\mathrm{MgO}-\mathrm{SiO} 2, \mathrm{MgO}-\mathrm{FeO}-\mathrm{SiO} 2$ and $\mathrm{CaO}-\mathrm{Al} 2 \mathrm{O} 3-\mathrm{SiO} 2$ [14,16], and the most highly represented minerals in slag are dicalcium and tricalcium silicates, while different aluminates and silicates are likely to appear as well [17]. 


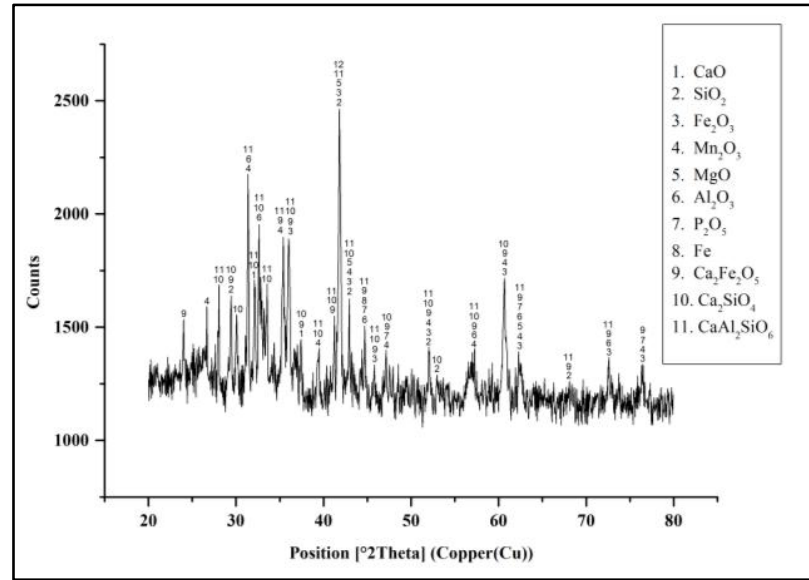

Figure 4: XRD pattern of unreacted EAFS

\subsection{Inductively Coupled Plasma Optical Emission Spectrometry}

Inductively Coupled Plasma Optical Emission Spectrometry (ICP-OES) is an elemental analytical technique used to determine the composition of a wide variety of materials in liquid form, with excellent sensitivity. In this study, leachates from the experiments manipulating the initial concentration of $\mathrm{HCl}$ and EAFS size were diluted and sent for elemental analysis using Inductively Coupled Plasma Optical Emission Spectrometer (model Optima 7300DV, Perkin-Elmer, USA) to determine the concentration of the elements $\mathrm{Fe}$ and $\mathrm{Ca}$. Calibration curves for $\mathrm{Fe}$ and $\mathrm{Ca}$ of known concentration $0 \mathrm{ppm}-9 \mathrm{ppm}$ and $0 \mathrm{ppm}-90 \mathrm{ppm}$, respectively was prepared for the determination of concentration of $\mathrm{Fe}$ and $\mathrm{Ca}$ in the samples.

\section{Conclusion}

In this review, widespread usage of slags as a byproduct of steel making industries in various applications have been discussed. On the other hand, $\mathrm{XRD}$ and SEM are used to determine the mineral compostion of steel slag. Based on the literature studies, it is pretty obvious that slags can be the promising replacements for conventional way of application of adsorbent and binder in various fields such as adsorption, construction, road and waste water treatment. The ease of use, low cost, and sources availability are among the few advantages on reusing and utizing the steel slag

\section{Acknowledgement}

The authors would like to gratefully acknowledge Ministry of Higher Education (MOHE), and Universiti Putra Malaysia (UPM) for the financial support of this work.

\section{References}

[1] T.C. Alex , A.M. Kalinkin, S.K. Nath, B.I. Gurevich , E.V. Kalinkina , V.V. Tyukavkina , S. Kumar, Utilization of zinc slag through geopolymerization: Influence of milling atmosphere, International Journal of Mineral Processing 123 (2013)102-107.
[2] http://geology.about.com/bio/Andrew-Alden 453.htm. Accessed on 14 January 2015

[3] EUROSLAG. Retrieved from http://www.euroslag.com/products/statistics/2010/. 4 March 2015

[4] M. Frias, M. I. Sanchez de Rojas, C. Rodriguez, The influence of SiMn slag on chemical resistance of blended cement pastes, Construction and Building Materials , 23(2009)1472-1475.

[5] P. Suer, J.E. Lindqvist, M. Arm, P. FrognerKockum, Reproducing ten years of road ageing accelerated carbonation and leaching of EAF steel slag, Science of The total Environment, 407(2009)5110-5118.

[6] M. Ameri, S. Hesami, H. Goli, Laboratory evaluation of warm mix asphalt mixtures containing electric arc furnace (EAF) steel slag, Construction and Building Materials, 49(2013) 611-617.

[7] K. Yamashita, T. Ikenata, K. Tate, K. Nakahara, Method of Removing Dissolved Heavy Metals from Aqueous Waste Liquids, US Patent, 4377483, (1983).

[8] M.R. Nilforoushan, S. Otroj, Absorption of Lead Ions by Various Types of Steel Slag, Iranian Journal of Chemistry \& Chemical Engineering 27(2008)69-75.

[9] A. Drizo, C. Forget, R.P. Chapuis, Y. Comeau, Phosphorus removal by electric arcfurnace steel slag and serpentinite. Water Research, 40(2006)1547-1554.

[10] F. Chazarenc, J. Brisson, Y. Comeau, Slag columns for upgrading phosphorus removal from constructed wetland effluents. Water Science Technology 56(2007)109-115.

[11] C. Vohla, M. Koiv, H.J. Bavor, F. Chazarenc, U. Mander, Filter materials for phosphorus removal from wastewater in treatment wetlands-A review. Ecological Engineering, 37(2011)70-89.

[12] C. Pratt, A. Shilton, Active slag filters-simple and sustainable phosphorus removal from wastewater using steel industry byproduct. Water Science and Technology, 62 (2010)1713-1718.

[13] Bankole, L., Rezan, S. and Sharif, N. Assessment of hexavalent chromium release in Malaysian electric arc furnace steel slag for fertilizer usage. IOP Conf. Ser.: Earth Environ. Sci., 19, 012004. doi:10.1088/1755-1315/19/1/012004 (2014)

[14] Yildirim, I. andPrezzi, M. Chemical, mineralogical, and morphological properties of steel slag. Advances In Civil Engineering, 2011, 1-13. doi:10.1155/2011/463638 (2011)

[15] Nwaubani, S. andMuntasser, T. Hydration characteristics of cement pastes incorporating electric 
arc-furnace slag. Journal Of Civil Engineering And Construction Technology, 3(11), 291-301. doi:10.5897/JCECT12.043 (2012)

[16] Rađenović, A., Malina, J. andSofilić, T. Characterization of ladle furnace slag from carbon steel production as a potential adsorbent. Advances In Materials Science And Engineering, 2013, 1-6. doi:10.1155/2013/198240 (2013)
[17] Selih, J., Ducman, V., Mladenovič, a., Sever, S.A., Pavšič, P..Makarovič, M. and Legat, A. The use of waste materials in building and civil engineering in Slovenian. Mater.Techno. Ljubljana 38: 79-86. (2004) 